\title{
Renal colic causing Boerhaave syndrome
}

\author{
Dylan Barnett ${ }^{1}$, Ned Kinnear ${ }^{2}$, Henry Han-I Yao ${ }^{2}$, Justin Chee ${ }^{2}$ \\ ${ }^{1}$ Department of Urology, Royal Adelaide Hospital, Adelaide, Australia; ${ }^{2}$ Department of Urology, Footscray Hospital, Footscray, Melbourne, Australia \\ Correspondence to: Dr. Ned Kinnear. Department of Urology, Footscray Hospital, 160 Gordon St, Footscray, VIC 3011, Australia. \\ Email: ned.kinnear@adelaide.edu.au.
}

\begin{abstract}
Boerhaave syndrome is the spontaneous rupture of the oesophagus, usually due to vomiting. The condition is rare but can be fatal. A 30-year-old male presented with vomiting and pain in his left flank and chest. Computed tomography scanning of the chest, abdomen and pelvic revealed a $4 \mathrm{~mm}$ left proximal ureteric stone and pneumo-mediastinum due to oesophageal rupture, consistent with Boerhaave syndrome. The patient underwent insertion of left ureteric stent, with staged left ureteroscopy and laser lithotripsy. The patient's oesophageal rupture was managed conservatively, and he made a full recovery. This is only the second report of renal colic causing Boerhaave syndrome.
\end{abstract}

Keywords: Renal colic; urolithiasis; Boerhaave; oesophageal rupture; oesophageal perforation

Submitted Aug 07, 2019. Accepted for publication Nov 29, 2019.

doi: $10.21037 /$ tau. 2019.12 .11

View this article at: http://dx.doi.org/10.21037/tau.2019.12.11

\section{Introduction}

Vomiting is common in patients with renal colic but concurrent oesophageal perforation is extremely rare. Boerhaave syndrome is spontaneous oesophageal perforation. Typically caused by vomiting, it remains rare and has a high mortality. This represents only the second reported case of the syndrome secondary to renal colicinduced vomiting.

\section{Case presentation}

A 30-year-old male presented with a one-day history of acute left flank pain, associated with vomiting and mild chest pain. The patient denied any significant past medical history. The patient smoked four cigarettes per today and consumed ten standard drinks of alcohol per week. He took no regular medications.

On examination the patient was well. Temperature was $38.3{ }^{\circ} \mathrm{C}$. Other vital signs were normal. Chest and abdominal examination were unremarkable. Urine dipstick was positive for blood, and negative for leucocyte esterase or nitrites. White cell count was $21 \times 10^{9} / \mathrm{L}, \mathrm{C}$-reactive protein (CRP) $16 \mathrm{mg} / \mathrm{L}$ and estimated glomerular filtration rate (eGFR) $53 \mathrm{~mL} / \mathrm{min} / 1.73 \mathrm{~m}^{2}$. Other values were normal.
Contrast computerised tomography (CT) scan of the chest, abdomen and pelvis (CAP) revealed small volume pneumomediastinum surrounding the oesophagus, and a $4 \mathrm{~mm}$ left proximal ureteric calculus with left hydronephrosis (Figure 1). Non-obstructing bilateral renal calculi were also present.

The patient was assessed as having a left ureteric calculus with secondary oesophageal perforation due to forceful vomiting. In multi-disciplinary management involving urology, upper gastrointestinal surgery and intensive care specialists, blood and urine cultures were sent, before commencing intravenous gentamicin $320 \mathrm{mg}$ daily and amoxicillin $1 \mathrm{~g}$ 6-hourly. The patient was kept nil by mouth and given intravenous fluid replacement. A 16-French urethral catheter was placed.

The following day, both the patient's chest and flank pain persisted but had decreased. His observations were unremarkable, including resolution of his fever. His serum investigations had largely improved, with WCC $14 \times 10^{9} / \mathrm{L}$, eGFR $80 \mathrm{~mL} / \mathrm{min} / 1.73 \mathrm{~m}^{2}$ and CRP $32 \mathrm{mg} / \mathrm{L}$. He proceeded to theatre, where he received rapid sequence induction of anaesthesia, avoiding positive pressure ventilation to reduce the risk of worsening the pneumomediastinum. The patient underwent rigid cystoscopy and insertion of 6-French left ureteric JJ stent under 

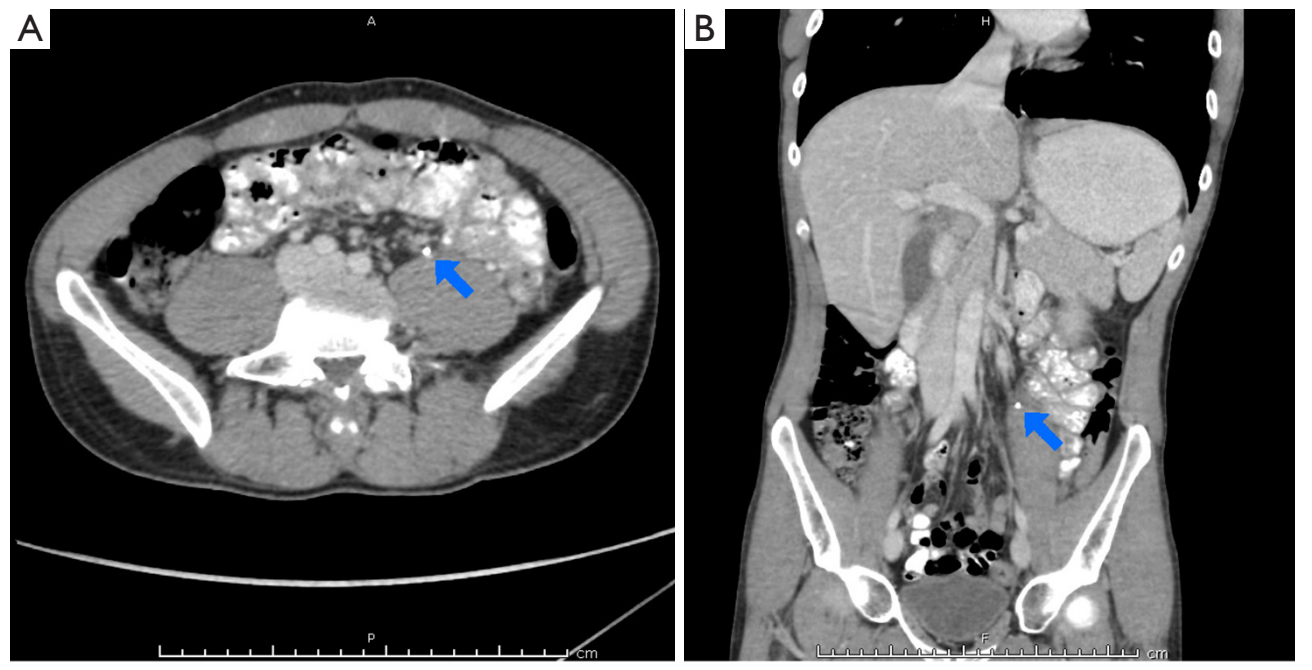

Figure 1 Contrast CT scan of the abdomen and pelvis, coronal and axial slices. A 4 mm left proximal ureteric stone is present (blue arrow), with proximal hydronephrosis (not shown).

fluoroscopic guidance.

The following day, the patient's symptoms and serum investigations were further improved. Gastrografin swallow revealed a normal oesophagus, without contrast leak into the mediastinum. Blood and urine cultures were confirmed as negative. The patient was discharged on prophylactic oral amoxicillin/ clavulanic acid 875/125 mg twice a day for five days.

Following chest $\mathrm{X}$-ray to rule out new pneumothorax, four weeks later that patient received rigid cystoscopy, left ureteropyeloscopy and laser lithotripsy, with excellent stone clearance. His ureteric stent was exchanged, and the patient discharged the same day. Two weeks later, the patient underwent flexible cystoscopy and removal of his stent under local anaesthesia. The patient remains well at four months' follow up.

\section{Discussion}

In 1724, Herman Boerhaave first described oesophageal perforation secondary to raised intra-abdominal pressure (1). Classically, gastric contents spill into the mediastinum causing a chemical and later septic mediastinitis. Vomiting is the typical cause, but other aetiologies include blunt trauma, weightlifting, parturition, defecation and seizures $(1,2)$. There is only a single prior report of Boerhaave syndrome secondary to renal colicinduced vomiting (3).

Patients typically report chest or upper abdominal pain and dysphagia. Examination reveals tachypnoea and lowgrade fever then progressive cardiovascular compromise and septic shock if untreated. Pneumo-mediastinum may cause Hamman's sign (crackling on auscultation accompanying each systole) or subcutaneous emphysema (2). Mackler's triad of lower chest pain, vomiting and subcutaneous emphysema is seen only in a minority of patients (4).

Plain chest $\mathrm{X}$-ray may reveal pleural effusion, pneumomediastinum, subcutaneous emphysema, hydropneumothorax and pneumothorax (1). Gastrografin (sodium amidotrizoate) swallow is favoured over barium because it does not contribute to inflammation (2). Crosssectional imaging is extremely useful for patients where the diagnosis is in doubt. CT CAP is a sensitive study for demonstrating free mediastinal gas, associated sequelae and ruling out other causes of acute abdomen. Endoscopy is diagnostic and potentially therapeutic via placement of a nasogastric tube, endoluminal stent or metal clips, but mandates an expert endoscopist $(4,5)$.

Boerhaave syndrome is commonly fatal if left untreated (2). Initial management consists of intravenous access, resuscitation and early involvement of critical care specialists. Attention must be paid to the treating the cause, such as renal colic in this case. As in this case, conservative management may be considered in a stable patient with no mediastinitis, and involves close monitoring, care, nil by mouth, broad-spectrum intravenous antibiotics and potentially antifungal agents.

Surgical intervention is required if patient is septic, 
has gross mediastinal contamination or fails non-operative management. It includes oesophageal access via posterolateral thoracotomy or video-assisted thoracoscopic surgery and mediastinal washout $(1,2,4)$. Oesophageal repair may be immediate primary, placement of oesophago-cutaneous T-tube or delayed oesophagectomy $(1,4)$.

Vomiting is common in patients with renal colic but concurrent spontaneous oesophageal perforation is extremely rare. This patient was fortunate to have only small volume pnemo-mediastinum, no spillage of gastric contents and early antibiotics.

Boerhaave syndrome is rare but potentially fatal and may complicate vomiting of any aetiology. This report represents only the second report of the syndrome secondary to renal colic-induced vomiting.

\section{Acknowledgments}

Funding: None.

\section{Footnote}

Conflicts of Interest: All authors have completed the ICMJE uniform disclosure form (available at http://dx.doi. org/10.21037/tau.2019.12.11). The authors have no conflicts of interest to declare.

Etbical Statement: The authors are accountable for all aspects of the work in ensuring that questions related to the accuracy or integrity of any part of the work are appropriately investigated and resolved. Written consent was obtained for publication of this case report.

Open Access Statement: This is an Open Access article distributed in accordance with the Creative Commons Attribution-NonCommercial-NoDerivs 4.0 International License (CC BY-NC-ND 4.0), which permits the noncommercial replication and distribution of the article with the strict proviso that no changes or edits are made and the original work is properly cited (including links to both the formal publication through the relevant DOI and the license). See: https://creativecommons.org/licenses/by-nc$\mathrm{nd} / 4.0 /$.

\section{References}

1. Griffin SM, Lamb P. Oesophagogastric surgery. 6th ed. Edinburgh, New York: Saunders/Elsevier; 2018.

2. Turner AR, Turner SD. Boerhaave Syndrome. StatPearls [Internet]. StatPearls Publishing, Treasure Island, USA. 2017 Apr 19. PMID: 28613559. Accessed 25 Aug 2018. Available online: https://www.ncbi.nlm.nih.gov/books/ NBK430808/

3. Liao WI, Liu CC, Huang TW, et al. Boerhaave Syndrome Secondary to Renal Colic. J Med Sci 2009;29:225-8.

4. Griffin SM, Lamb PJ, Shenfine J, et al. Spontaneous rupture of the oesophagus. Br J Surg 2008;95:1115-20.

5. Tellechea JI, Gonzalez JM, Miranda-García P, et al. Role of Endoscopy in the Management of Boerhaave Syndrome. Clin Endosc 2018;51:186-91.
Cite this article as: Barnett D, Kinnear N, Yao HH, Chee J. Renal colic causing Boerhaave syndrome. Transl Androl Urol 2020;9(2):828-830. doi: 10.21037/tau.2019.12.11 